\title{
PENERAPAN METODE K-MEANS UNTUK PROSES PENENTUAN GOLONGAN PENERIMA ZAKAT (MUSTAHIQ) DI YAYASAN DANA SOSIAL AL-FALAH MALANG
}

\author{
Eka Puji Lestari ${ }^{1}$, Ali Mahmudi ${ }^{2}$, Sentot Achmadi $^{3}$ \\ Program Studi Teknik Informatika S1, Fakultas Teknologi Industri \\ Institut Teknologi Nasional Malang, Jalan Raya Karanglo km 2 Malang, Indonesia \\ ekapujilestari2697@gmail.com
}

\begin{abstract}
ABSTRAK
Yayasan Dana Sosial Al-Falah Malang atau YDSF merupakan lembaga Pendayagunaan Dana, dan Penghimpun Dana yang memiliki beberapa program bantuan diantaranya yaitu Pendidikan, Soskem, Dakwah, Masjid dan Yatim. Dalam proses penentuan golongan penerima zakat atau mustahiq sampai saat ini masih dilakukam secara manual. Sehingga membutuhkan waktu yang lama dan memiliki kemungkinan terjadi kesalahan saat menentukan golongan penerima zakat atau mustahiq. Sehingga dapat menimbulkan kesenjangan sosial karena perbedaan jumlah zakat yang diterima mustahiq.

Pada penelitian ini, dibuatlah sebuah sistem yang menerapkan metode K-Means untuk proses penentuan golongan penerima zakat (mustahiq) yang tepat sasaran dan cepat. Sehingga dapat memudahkan lembaga dan dapat mempersingkat waktu dalam pengolahan data. Kriteria yang digunakan pada sistem ada 13 kriteria yaitu pekerjaan, pendapatan, pekerjaan istri, pendapatan istri, jumlah anak, tanggungan, kepemilikan rumah, lantai rumah, dinding rumah, elektronik, transportasi, daya listrik dan biaya listrik. Sistem yang dirancang menggunakan bahasa pemograman PHP (Hypertext Preprocessor) dengan Database MySQL.

Hasil pengujian sistem dengan menerapkan metode K-Means untuk proses penentuan golongan penerima zakat (mustahiq), menghasilkan tingkat akurasi 75\%. Pengujian algoritma ini dilakukan dengan membandingkan golongan pada data lama dengan golongan hasil perhitungan. Dengan adanya sistem ini diharapkan dapat membantu lembaga YDSF dalam penentukan golongan penerima zakat (mustahiq) dengan cepat dan akurat.
\end{abstract}

Kata kunci : K-Means, golongan penerima zakat (mustahiq), lembaga zakat, zakat, $p h p, M y S Q L$.

\section{PENDAHULUAN}

\subsection{Latar Belakang}

Yayasan Dana Sosial Al-Falah (YDSF) adalah Lembaga Amil Zakat Nasional (LAZNAS) yang didirikan pada tanggal 1 Maret 1987 oleh para tokoh, ulama, dan pengusaha muslim di Masjid al-Falah Surabaya. YDSF merupakan lembaga Pendayagunaan Dana, dan Penghimpun Dana yang memiliki beberapa program bantuan diantaranya Pendidikan, Soskem, Dakwah, Masjid dan Yatim.

Ketepatan dalam proses penyaluran zakat untuk golongan mustahiq sangat diperhatikan oleh YDSF, dimana kriteria dan pertimbangan lainnya harus diperhitungkan sebagai alternatif dalam penilaian agar penyaluran lebih tepat dan tidak salah sasaran. Namun dalam proses penyaluran zakat, biasanya sering terjadi kendala untuk penentuan golongan penerima zakat atau mustahiq berdasarkan data hasil survei. Kendala tersebut dikarenakan banyaknya data mustahiq yang membuat kesulitan dalam memproses data karena membutuhkan waktu yang lama dan memiliki kemungkinan yang lebih besar menghasilkan kesalahan saat menentukan golongan penerima zakat atau mustahiq. Sehingga dapat menimbulkan kesenjangan sosial karena perbedaan jumlah zakat yang diterima mustahiq.

Proses pengolahan dan penyimpanan data hasil survei mustahiq, YDSF sudah menggunakan peran teknologi yaitu Microsoft Excel dan Microsoft Word. Setelah melakukan survei data calon mustahiq di masukan secara manual lagi ke Microsoft Word dan kemudian di rekap lagi pada Microsoft Excel. hal tersebut membutuhkan waktu yang lama dalam memproses data dan penentuan golongan mustahiq.

Oleh karena itu, perlu adanya pengembangan sistem yang dapat membantu lembaga dalam menentukan golongan penerima zakat atau mustahiq. Dalam proses penentuan golongan mustahiq, yaitu berdasarkan kriteria hasil survei yang kemudian akan diproses dengan perhitungan metode K-Means. Karena metode tersebut mengelompokan data berdasarkan kriteria yang memiliki karekteristik yang sama, selain itu metode K-means dapat mengelompokan objek besar sehingga mempercepat proses pengelompokan. Sehingga dapat mempersingkat waktu dalam memproses data.

\subsection{Rumusan Masalah}

Sehubungan dengan latar belakang yang diuraikan, maka dirumuskan beberapa masalah yaitu :

1. Bagaimana membuat Aplikasi yang dapat menghasilkan laporan dalam waktu yang cepat dan akurat?

2. Bagaimana membuat aplikasi penentuan golongan penerima zakat atau mustahiq dengan menggunakan metode K-means di Yayasan Dana Sosial Al-Falah Malang? 


\subsection{Batasan Masalah}

Batasan masalah dari pembuatan aplikasi dengan menggunakan metode K-Means untuk proses penentuan golongan penerima zakat atau mustahiq di Yayasan Dana Sosial Al-Falah Malang adalah sebagai berikut :

1. Data yang digunakan adalah data mustahiq yang ada pada YDSF.

2. Kriteria yang digunakan ada 13 yang terdiri dari pekerjaan, pendapatan, pekerjaan istri, pendapatan istri, jumlah anak, tanggungan, kepemilikan rumah, lantai rumah, dinding rumah, elektronik, transportasi, listrik, dan biaya listrik.Metode yang digunakan adalah metode K-Means, digunakan untuk menentukan golongan penerima zakat atau mustahiq.

3. Bahasa yang digunakan untuk mengembangkan sistem adalah bahasa pemrograman Php dengan database MySQL.

4. Aplikasi yang akan di kembangkan berbasis web.

5. Data set yang digunakan 40 data.

\subsection{Tujuan}

Tujuan yang hendak dicapai dalam perancangan sistem ini adalah sebagai berikut:

1. Untuk membuat aplikasi yang dapat menghasilkan laporan yang lebih cepat dan akurat.

2. Membuat aplikasi dengan menerapkan metode KMeans dalam rangka penentuan golongan penerima zakat atau mustahiq di kota Malang.

\section{TINJAUAN PUSTAKA}

\subsection{Penelitian Terkait}

Dalam suatu penelitian diperlukan dukungan hasil-hasil penelitian yang telah ada sebelumnya, yang berkaitan dengan penelitian tersebut. Begitupun dengan penelitian penentuan mustahiq juga diperlukan dukungan hasil dari penelitian yang telah ada.

Di tahun 2016, Afrianty dan Umbara mengembangkan sistem pendukung keputusan menentukan kelayakan calon penerima zakat dengan menerapkan metode Multi-factor Evaluation Prosses (MFEP). Dalam penelitian, mereka mengungkapkan bahwa calon penerima zakat yang direkomendasikan yaitu yang memiliki bobot yang paling besar dari perhitungan yang menggunakan metode MFEP, dengan kriteria yang telah ditentukan yaitu kondisi kemampuan keluarga, pendapatan dan tanggungan, tempat tinggal, kepemilikan barang dan karakter.[1]

Di tahun berikutnya (2017), Sulastri dan Ghufroni mengembangkan sistem untuk pengelompokan penderita Thalassaemia dengan menerapkan metode K-means. Penelitian mereka menggunakan kriteria yang terdiri dari umur, $\mathrm{Hb}$ level dan jumlah darah dengan tujuan untuk mengelompokan data kriteria penderita Thalassaemia. Hasil penelitian menunjukan bahwa penderita Thalassaemia menggunakan algoritma Kmeans clustering menjadi 3 kelompok, yaitu untuk kelompok 1 berjumlah 214 data, kelompok 2 berjumlah 138 data, dan kelompok 3 berjumlah 23 data. Dalam penggunaan metode K-Means penentuan titik pusat awal (centroid) sangat berpengaruh terhadap jumlah iterasi yang akan dihitung.[2]

Di tahun berikutnya (2018), Iswara dan kawan-kawan mengembangkan sistem pendukung keputusan untuk menentukan mustahiq (penerima zakat) menggunakan metode fuzzy AHP (F-AHP). Penelitian mereka menggunakan beberapa kriteria yaitu status anak, jumlah penghasilan, jumlah tanggungan dan nilai raport anak. Kriteria tersebut akan menentukan mana yang paling layak mendapatkan dana zakat. Hasil penelitian menunjukan bahwa jika hasil perhitungan jumlah bobot alternative besar sama dengan jumlah bobot batas maka berhak menerima zakat.[3]

\subsection{Metode K-Means}

K-Means clustering merupakan salah satu metode yang mengelompokan data ke dalam satu atau lebih kelompok/cluster. Dalam satu kelompok/cluster memiliki anggota berupa data-data yang memiliki karakteristik yang sama dan data yang memiliki karakteristik yang berbeda dikelompokan dengan kelompok/cluster yang lain sehingga dalam satu kelompok/cluster memiliki data yang tingkat variasinya kecil [4].

langkah-langkah untuk melakukan proses cluster dengan metode K-Means adalah sebagai berikut [5] :

1. Pilih jumlah cluster $\mathrm{k}$.

2. Inisialisasi kpusat clusterini bisa dilakukan dengan berbagai cara. Namun yang paling sering dilakukan adalah dengan cara random. Pusatpusat cluster diberiduberi nilai awal dengan angkaangka random.

3. Alokasikan semua data/ objek ke cluster terdekat. Kedekatan dua objek ditentukan berdasarkan jarak kedua objek tersebut. Demikian juga kedekatan suatu data ke cluster tertentu ditentukan jarak antara data dengan pusat cluster.

Dalam tahap ini perlu dihitung jarak tiap data ke tiap pusat cluster. Jarak paling antara satu data dengan satu clustertertentu akan menentukan suatu data masuk dalam cluster mana. Untuk menghiutng jarak semua data ke setiap tiitk pusat cluster dapat menggunakan teori jarak Euclidean yang dirumuskan sebagai berikut:

$$
\begin{aligned}
& D(i, j)=\sqrt{\left(X_{1 i}-X_{1 j}\right)^{2}+\left(X_{2 u}-X_{2 j}\right)^{2}+\cdots+\left(X_{k l}-X_{k j}\right)^{2}} \ldots \text { (1) } \\
& \text { dimana: } \\
& D(i, j)=\text { Jarak data ke } i \text { ke pusat cluster } j \\
& X_{k i} \text { - Data ke } i \text { pada atribut data ke } k \\
& X_{k j}=\text { Titik pusat ke } j \text { pada atribut ke } k
\end{aligned}
$$

4. Hitung kembali pusat cluster dengan keanggotaan cluster yang sekarang. Pusatcluster adalah ratarata dari data/objek dalam cluster tertentu. Jika dikehendaki bisa juga menggunakan median dari cluster tersebut. Jadi rata-rata (mean) bukan satusatunya ukuran yang bisa dipakai.

5. Tugaskan lagi setiap objek memakai pusat cluster yang baru. Jika pusat cluster tidak berubah lagi maka 
proses clustering selesai. Atau, kembali ke langkah nomor 3 sampai pusat cluster tidak berubah lagi. [6]

\section{METODE PENELITIAN}

\subsection{Analisis Sistem}

Sistem proses penentuan golongan penerima zakat (mustahiq) yang akan dibuat berbasis web dengan menggunakan metode K-Means. Data yang digunakan adalah data Penerima zakat (mustahiq) di Yayasan Dana Sosial Al-Falah di Kota Malang.

Diharapkan sistem yang dikembangkan dengan menerapkan metode K-Means, dapat membantu lembaga untuk menentukan golongan penerima zakat (mustahiq) sehingga dapat mempersingkat waktu dalam penentuan golongan penerima zakat (mustahiq) dan mengolah data. Dengan begitu dapat menanggulangi kesalahan dalam menentukan golongan penerima zakat (mustahiq) saat penyaluran zakat karena salah sasaran, sehingga terjadinya kesenjangan sosial karena adanya perbedaan jumlah zakat yang diterima.

Desain sistem penentuan golongan penerima zakat (mustahiq) dikembangkan dalam penelitian ini menggunakan metode K-Means di tunjukkan pada gambar 1

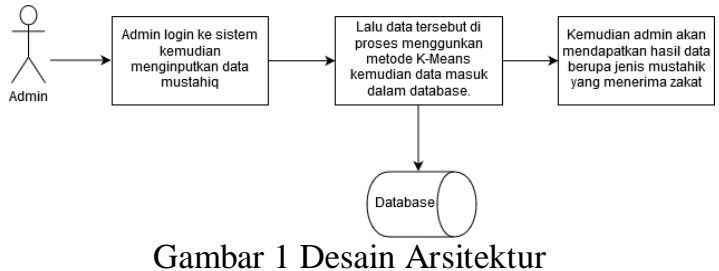

Blok diagram sistem pada Gambar 1 dapat diketahui langkah awal sebelum menjalankan aplikasi yaitu admin sebagai hak ases membuka sistem kemudian login. Setelah masuk kedalam sistem admin menginputkan data mustahiq. Kemudian data tersebut di proses menggunakan metode K-Means dan masuk kedalam database. Lalu muncul hasil berupa golongan mustahiq yang menerima zakat.

\subsection{Flowchart Sistem}

Flowchart yang dibuat untuk menggambarkan alur dari sistem ini adalah sebagai berikut :

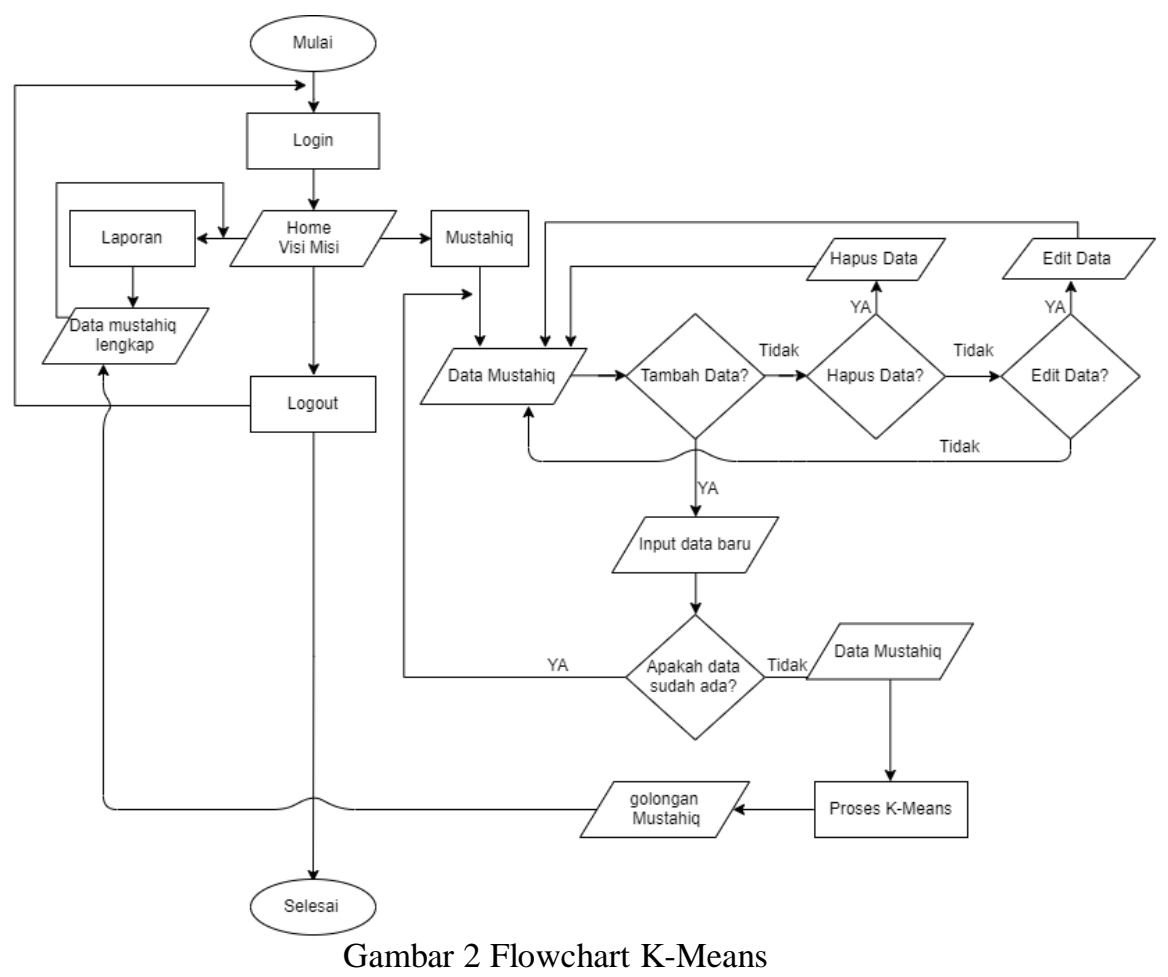

Penjelasan flowchart sistem pada gambar 2 yaitu:

\section{Home}

Saat admin membuka sistem, admin sebagai hak ases penuh dapat memasukan username dan password. Setelah masuk dan muncul tampilan home, admin dapat melihat visi misi YDSF.

2. Data Mustahiq

Saat admin masuk pada data mustahiq, admin dapat melihat data mustahiq dan dapat menambahkan data mustahiq baru dengan kriteria-kriteria yang telah di tentukan . Pada saat menambah data baru dan ternyata data sudah ada maka data tidak akan di proses dan admin akan dikembalikan pada halaman data mustahiq. Namun apabila data mustahiq baru yang diinputkan belum ada maka data akan di simpan ke data mustahiq lalu ada button proses yang digunakan untuk memproses data mustahiq menggunakan metode K-Means. Setelah data di proses data akan disimpan secara otomatis di 
menu Laporan dan menu golongan dan hasil proses akan muncul. Hasil proses berupa golongan penerima zakat atau mustahiq. Selain itu di menu data mustahiq admin dapat menghapus dan mengubah data.

3. Laporan

Menu laporan terdapat data mustahiq yang lengkap dengan kriteria- kriterianya. Pada halaman laporan terdapat fitur export to excel untuk mencetak data ke excel.

4. Logout

Menu Logout berfungsi untuk admin yang ingin keluar dari sistem dan akan di kembalikan ke halaman login.

\subsection{Struktur Menu}

Struktur menu merupakan struktur yang menampilkan menu apa saja yang terdapat didalam aplikasi. Struktur menu yang akan dirancang di dalam aplikasi ini ditunjukan seperti pada Gambar 3 .

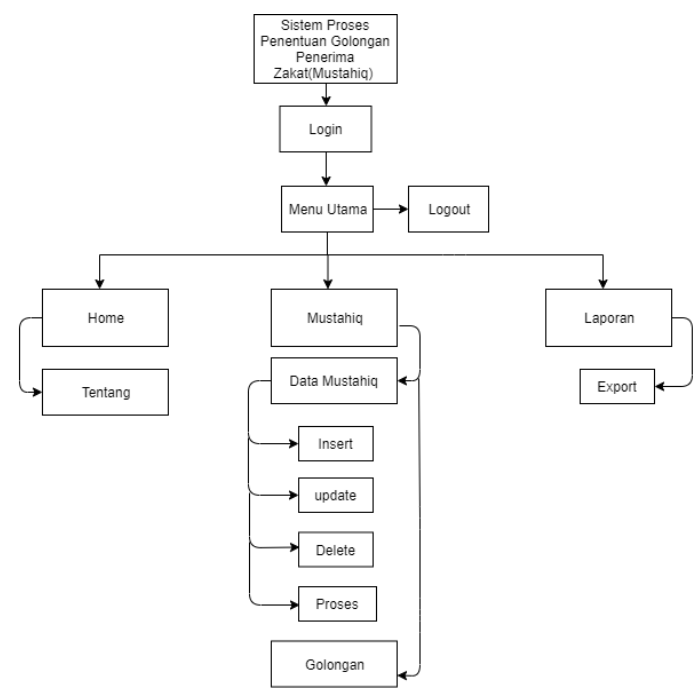

Gambar 3 Struktur Menu

Gambar 3 adalah alur menu secara keseluruhan, admin dapat melakukan proses login, input, ubah, delete data mustahiq dan menampilkan hasil golongan mustahiq.

\section{HASIL DAN PEMBAHASAN \\ 4.1 Implementasi \\ 1. Halaman Data Mustahiq}

Halaman ini berfungsi untuk menampilkan nama dan alamat mustahiq serta terdapat fitur edit dan delete untuk menambah, mangubah dan menghapus data mustahiq. Selain itu, juga terdapat fitur pencarian dan proses untuk metode K-Means, seperti pada Gambar 4.

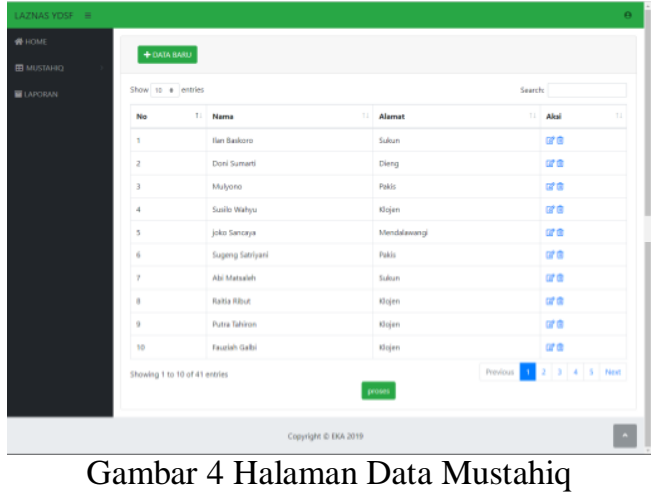

\section{Halaman Tambah data baru}

Menu data baru berfungsi untuk menambahkan data mustahiq. Terdapat kolom kriteria yaitu nama, alamat, pendidikan, pekerjaan, pendapatan, pekerjaan istri, pendapatan istri, jumlah anak, tanggungan, kepemilikan rumah, lantai rumah, dinding rumah, elektronik, transportasi, daya listrik, dan biaya listrik. Kemudian setelah semua data sudah di input-kan selanjutnya pilih Button simpan, maka data akan ditambahkan ke tabel halaman data mustahiq dan ke database. Data yang tampil pada halaman mustahiq yaitu nama mustahiq dan alamat mustahiq. Tampilan halaman input data dapat dilihat pada Gambar 5.

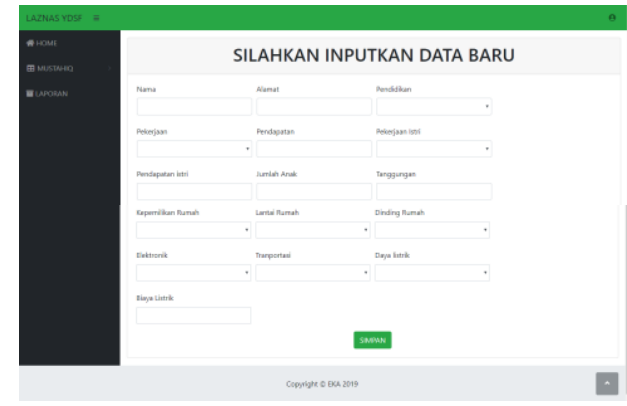

Gambar 5 Halaman input data baru

\section{Halaman Golongan}

Halaman golongan menampilkan hasil perhitungan dari metode K-Means saat button proses di klik. Tampilan halaman seperti yang ditunjukkan pada Gambar 6

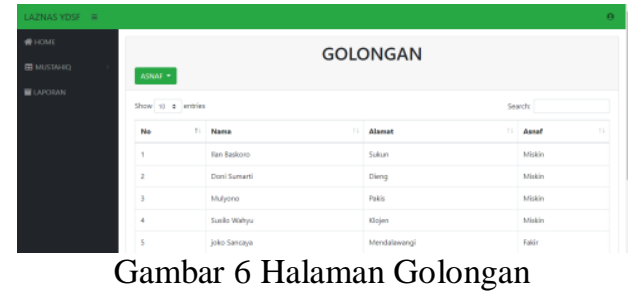




\section{Halaman Laporan}

Halaman Laporan menampilkan data mustahiq secara lengkap dengan golongan penerima zakat yang dihasilkan dari perhitungan K-Means. Pada halaman laporan terdapat fitur export to excel dimana admin dapat mencetak data mustahiq.Tampilan halaman seperti pada Gambar 7 dibawah ini.

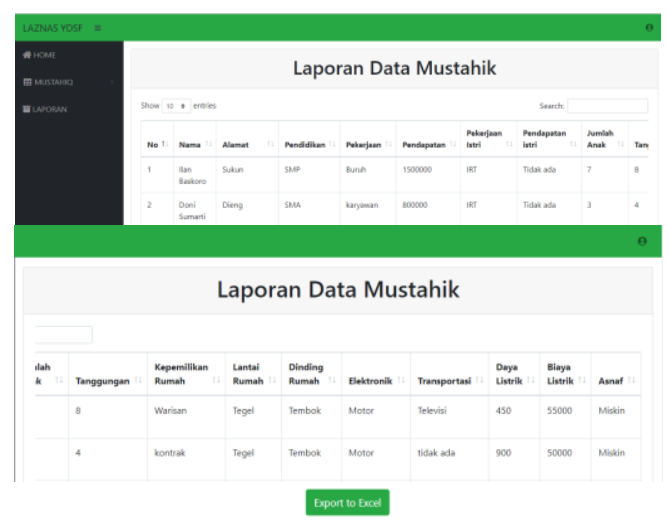

Gambar 7 Halaman Laporan

\subsection{Pengujian sistem}

Pengujian sistem merupakan tahap uji coba sistem untuk menguji setiap fungsi vital agar nantinya dapat diambil kesimpulan apakah sistem berjalan dengan baik sesuai tujuan awal pembuatan aplikasi.

\section{a. Pengujian fungsional sistem}

Tabel 1 Pengujian Sistem

\begin{tabular}{|c|l|c|c|}
\hline No. & \multicolumn{1}{|c|}{ Fungsi Yang Diuji } & B & G \\
\hline 1. & Login & $\sqrt{ }$ & - \\
\hline 2. & Halaman Data Santri & & \\
\hline & a. Tambah Data & $\sqrt{ }$ & - \\
\hline & b. Ubah Data & $\sqrt{ }$ & - \\
\hline & c. Hapus Data & $\sqrt{ }$ & - \\
\hline 3. & Golongan & $\sqrt{ }$ & - \\
\hline 4. & Laporan & $\sqrt{ }$ & \\
\hline 5. & Export to excel & $\sqrt{ }$ & \\
\hline 6. & Logout & $\sqrt{ }$ & - \\
\hline
\end{tabular}

Keterangan :

D $\mathrm{B}$ : Berhasil

$>$ G : Gagal

Berdasarkan hasil pungujian fungsional yang telah dilakukan mendapatkan hasil bahwa semua halaman, button dan laporan pada sistem yang dibuat telah berhasil dan berjalan dengan baik.

\section{b. Pengujian User}

Pengujian user bertujuan untuk mengetahui apakah sistem sudah berjalan dengan baik atau belum. Pengujian dilakukan terhadap 20 responden yaitu staf-staf dari Yayasan Dana Sosial Al-Falah Malang dan masyarakat. Kuesioner berisi 7 pertanyaan tentang aplikasi.

Berdasarkan hasil dari pengisihan kuesioner yang didapatkan peneliti dari responden menghasilkan persentase yang dapat dilihat pada Tabel 2.

Tabel 2 Pengujian User

\begin{tabular}{|c|c|c|c|c|}
\hline \multirow[b]{2}{*}{ No } & \multirow[b]{2}{*}{ Pertanyaan } & \multicolumn{3}{|c|}{ Penilaian } \\
\hline & & $\begin{array}{l}\text { 营 } \\
\text { 心 }\end{array}$ & 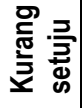 & 旁常 \\
\hline 1. & $\begin{array}{l}\text { Apakah ukuran dan } \\
\text { warna font tulisan } \\
\text { terlihat jelas? }\end{array}$ & $95 \%$ & $5 \%$ & $0 \%$ \\
\hline 2. & $\begin{array}{l}\text { Apakah warna tombol } \\
\text { dan background pada } \\
\text { aplikasi sudah terlihat } \\
\text { jelas? }\end{array}$ & $80 \%$ & $20 \%$ & $0 \%$ \\
\hline 3. & $\begin{array}{l}\text { Apakah alur menu pada } \\
\text { program mudah } \\
\text { dipahami? }\end{array}$ & $85 \%$ & $15 \%$ & $0 \%$ \\
\hline 4. & $\begin{array}{l}\text { Apakah form-form yang } \\
\text { ada pada program } \\
\text { sudah jelas dan mudah } \\
\text { digunakan? }\end{array}$ & $70 \%$ & $30 \%$ & $0 \%$ \\
\hline 5. & $\begin{array}{l}\text { Apakah kriteria data } \\
\text { yang digunkan sesuai } \\
\text { dengan kriteria mustahiq } \\
\text { yang ada di Yayasan } \\
\text { Dana Sosial Al-Falah } \\
\text { Malang? }\end{array}$ & $95 \%$ & $5 \%$ & $0 \%$ \\
\hline 6. & $\begin{array}{l}\text { Apakah sistem ini lebih } \\
\text { mempermudah } \\
\text { pekerjaan anda dalam } \\
\text { menentukan Golongan } \\
\text { penerima zakat } \\
\text { (mustahiq)? }\end{array}$ & $95 \%$ & $5 \%$ & $0 \%$ \\
\hline 7. & $\begin{array}{l}\text { Apakah sistem ini lebih } \\
\text { mempercepat pekerjaan } \\
\text { anda dalam dalam } \\
\text { menentukan Golongan } \\
\text { penerima zakat } \\
\text { (mustahiq)? }\end{array}$ & $85 \%$ & $15 \%$ & $0 \%$ \\
\hline
\end{tabular}

\subsection{Pengujian metode K-means}

Algoritma K-Means diperkenalkan oleh J.B. MacQueen pada tahun 1976. Metode ini mempartisi data ke dalam cluster (kelompok) sehingga data yang memiliki karakteristik yang sama dikelompokkan ke dalam cluster yang sama dan data yang mempunyai karakteristik berbeda dikelompokkan ke dalam kelompok yang lain [7]. Berikut perhitungan metode K-Means pada studi kasus Yayasan Dana Sosial AlFalah dalam menentukan golongan penerima zakat (mustahiq):

\section{Pembacaan Data Training}

Langkah pertama dalam menentukan data yang akan dianalisis dengan metode K-Means adalah membaca data training. Pada kasus penentuan penerima zakat atau mustahiq ada sejumlah 40 data training. Adapun data training yang digunakan dapat dilihat pada Tabel 3 
Tabel 3 Data Training

\begin{tabular}{|c|c|c|c|}
\hline No & Nama & Alamat & Golongan \\
\hline 1 & Ilan Baskoro & Sukun & miskin \\
\hline 2 & Doni Sumarti & Dieng & fakir \\
\hline 3 & Mulyono & Pakis & miskin \\
\hline 4 & Susilo Wahyu & Klojen & miskin \\
\hline 5 & joko Sancaya & Mendalawangi & miskin \\
\hline 6 & Sugeng Satriyani & Pakis & miskin \\
\hline 7 & Abi Matsaleh & Sukun & fakir \\
\hline 8 & Raitia Ribut & Klojen & miskin \\
\hline 9 & Putra Tahiron & Klojen & fakir \\
\hline 10 & Fauziah Galbi & Klojen & miskin \\
\hline 11 & Rahman Kurdi & Sukoharjo & miskin \\
\hline 12 & Rodzikin Pratama & kedung kandang & fakir \\
\hline 13 & iliyas fahmi & kedung kandang & miskin \\
\hline 14 & Kurniawan & kedung kandang & fakir \\
\hline 15 & yudha & sukun & fakir \\
\hline 16 & Dono janah & Klojen & miskin \\
\hline 17 & Ataraya said & sukun & fakir \\
\hline 18 & imam Khafidu & sukun & miskin \\
\hline 19 & hamzah mutakin & sukun & miskin \\
\hline 20 & Budiono sudari & sukun & miskin \\
\hline 21 & ahmad satria & lowokwaru & miskin \\
\hline 22 & Sumawito fathan & Binangun & miskin \\
\hline 23 & Irawan agus & Kalipare & miskin \\
\hline 24 & fadil abidin & Kalipare & fakir \\
\hline 25 & yusuf suwiknyo & Kalipare & fakir \\
\hline 26 & Yanto hasan & Kalipare & miskin \\
\hline 27 & Sukardi & Sukun & fakir \\
\hline 28 & Edi wahyu & Arjosari & miskin \\
\hline 29 & Imam andowu & Arjosari & miskin \\
\hline 30 & Limin kaselo & Arjosari & miskin \\
\hline 31 & Rama Rohman & Arjosari & fakir \\
\hline 32 & Busri Rofiq & Arjosari & fakir \\
\hline 33 & winarsi & lowokwaru & fakir \\
\hline 34 & Rimanto & kedung kandang & miskin \\
\hline 35 & Ratanto akbar & Klojen & fakir \\
\hline 36 & M.ghozali & Sukun & fakir \\
\hline 37 & M.imam & sukun & fakir \\
\hline 38 & Suwarto rahman & Klojen & miskin \\
\hline 39 & bambang krisna & rejosari & miskin \\
\hline 40 & m.rofii & blimbing & fakir \\
\hline
\end{tabular}

Data Training pada tabel 3 terdapat nama, alamat dan golongan. Lalu ada 13 data kriteria yang akan dilakukan proses perhitungan selanjutnya. Adapun data kriteria tersebut dapat dilihat pada tabel 4.

Tabel 4 Kriteria Data

\begin{tabular}{|c|c|}
\hline No & Kriteria \\
\hline 1 & Pekerjaan \\
\hline 2 & Pendapatan \\
\hline 3 & Pekerjaan istri \\
\hline 4 & Pendapatan istri \\
\hline 5 & Jumlah anak \\
\hline 6 & Tangggungan \\
\hline 7 & Kepemilikan rumah \\
\hline 8 & Lantai rumah \\
\hline 9 & Dinding rumah \\
\hline 10 & Elektronik \\
\hline 11 & Transportasi \\
\hline 12 & Daya listrik \\
\hline 13 & Biaya listrik \\
\hline
\end{tabular}

\section{Memberikan bobot pada setiap kriteria}

Memberikan bobot pada setiap kriteria memiliki tujuan yaitu agar semua data menjadi angka sehingga dapat dilakukan perhitungan. Cara memberikan bobot dapat dilihat pada Tabel 5
Tabel 5 Bobot pekerjaan

\begin{tabular}{|c|c|}
\hline Pekerjaan & Bobot \\
\hline Guru & 1 \\
\hline Karyawan & 2 \\
\hline Buruh & 3 \\
\hline Wiraswasta & 4 \\
\hline kuli & 5 \\
\hline Petani & 6 \\
\hline
\end{tabular}

Tabel 5 menunjukan nilai bobot pekerjaan, setiap kriteria harus memiliki bobot agar dapat dilakukan perhitungan.

Adapun data kriteria yang sudah diberikan bobot masing-masing seperti Tabel 6.

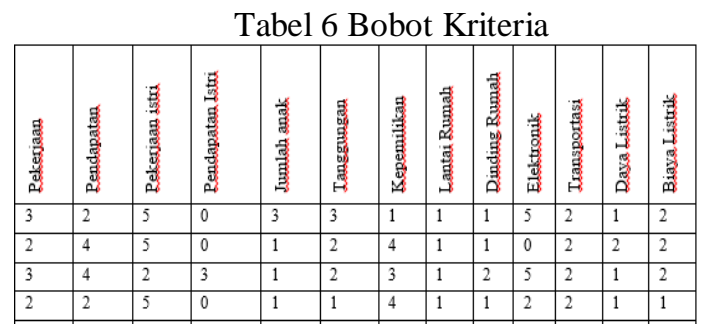

\section{Menentukan jumlah cluster dan nilai awal centroid}

Proses perhitungan penentuan golongan penerima zakat (mustahiq) akan digolongkan menjadi 2 golongan yaitu Fakir dan Miskin, sehingga memerlukan 2 cluster dan 2 centroid untuk proses perhitungan berikutnya. centroid awal dapat ditentukan secara random dari data mustahiq. Adapun nilai titik awal atau centroid dapat dilihat pada Tabel 7.

\section{Menghitung jarak setiap data ke pusat cluster menggunakan perhitungan jarak Euclidean.}

Proses ini bertujuan untuk mencari jarak terpendek antara objek ke centroid dengan rumus perhitungan jarak Euclidean. Rumus yang digunakan yaitu :

$$
D(K, C)=\sqrt{\sum_{i=1}^{n}\left(K_{i}-C_{i}\right)^{2}}
$$

Iterasi ke-1 :

Perhitungan data 1 untuk centroid 1 dan 2 menggunakan rumus jarak atau Euclidean: Jarak data dengan Centroid 1 :

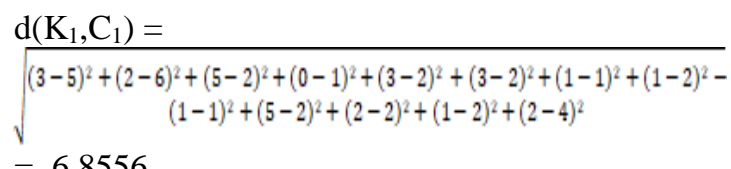

Jarak data dengan centroid 2 :

$\mathrm{d}\left(\mathrm{K}_{1}, \mathrm{C}_{2}\right)=$

$$
\begin{aligned}
& \sqrt{(3-6)^{2}+(2-6)^{2}+(5-0)^{2}+(0-0)^{2}+(3-1)^{2}+(3-1)^{2}+(1-2)^{2}+(1-2)^{2}-} \\
& \sqrt{(1-1)^{2}+(5-0)^{2}+(2-0)^{2}+(1-1)^{2}+(2-1)^{2}} \\
& =9.4868 \\
& \text { Dari hasil perhitungan di atas dapat disimpulkam } \\
& \text { bahwa jarak data mustahiq pertama yang paling dekat } \\
& \text { adalah cluster 1, sehingga mustahiq pertama }
\end{aligned}
$$


dimasukkan ke dalam cluster 1. Hasil perhitungan selengkapnya dapat dilihat pada tabel Tabel 8.

Tabel 8 Contoh hasil perhitungan data ke setiap cluster

\begin{tabular}{|c|c|c|}
\hline $\begin{array}{c}\text { Data } \\
\text { ke-i }\end{array}$ & $\mathbf{C 1}$ & $\mathbf{C 2}$ \\
\hline 1 & 6.8556546 & 9.486832981 \\
\hline 2 & 6.480740698 & 7.549834435 \\
\hline 3 & 5.744562647 & 7.745966692 \\
\hline 4 & 7.549834435 & 8.366600265 \\
\hline 5 & 5.291502622 & 5 \\
\hline 6 & 0 & 5.196152423 \\
\hline 7 & 6.633249581 & 6.244997998 \\
\hline 8 & 6.782329983 & 8.062257748 \\
\hline 9 & 6.08276253 & 7.483314774 \\
\hline 10 & 7.549834435 & 8.602325267 \\
\hline
\end{tabular}

\section{Kelompokan data sesuai cluster-nya}

Kelompokan data sesuai dengan cluster-nya yaitu data yang memiliki jarak terpendek. Jika $\mathrm{C} 1<\mathrm{C} 2$ maka jarak terpendeknya yaitu $\mathrm{C} 1$, begitupun sebaliknya. Adapun hasil pengelompokan data dapat dilihat pada Tabel 9

Tabel 9 Tabel pengelompokan cluster

\begin{tabular}{|c|c|c|}
\hline $\begin{array}{c}\text { Data } \\
\text { ke-i }\end{array}$ & $\min$ & Cluster \\
\hline 1 & 6.8556546 & 1 \\
\hline 2 & 6.480740698 & 1 \\
\hline 3 & 5.744562647 & 1 \\
\hline 4 & 7.549834435 & 1 \\
\hline 5 & 5 & 2 \\
\hline 6 & 0 & 1 \\
\hline 7 & 6.244997998 & 2 \\
\hline 8 & 6.782329983 & 1 \\
\hline 9 & 6.08276253 & 1 \\
\hline 10 & 7.549834435 & 1 \\
\hline
\end{tabular}

\section{Mencari nilai centroid baru}

Setelah mendapatkan label cluster untuk masingmasing data, maka dicari centroid baru untuk iterasi berikutnya dengan menjumlahkan seluruh anggota masing-masing cluster dibagi jumlah anggota cluster. Adapun hasil perhitungan untuk mencari centroid baru dapat dilihat di Tabel 10 .

Pada iterasi berikutnya perhitungan di ulang dari langkah ke-4 yaitu perhitungan jarak terdekat antar data dengan centroid. Centroid yang digunakan yaitu centroid baru dari setiap iterasi sebelumnya seperti tabel 10. Perulangan atau iterasi berhenti saat hasil cluster baru dari iterasi terakhir sama dengan cluster dari iterasi sebelumnya atau centroid baru sama dengan centroid lama. Hasil clustering dapat dilihat pada Tabel 11.

Tabel 11 Hasil clustering

\begin{tabular}{|c|c|c|}
\hline Data ke-i & Cluster 1 & Cluster 2 \\
\hline 1 & * & \\
\hline 2 & * & \\
\hline 3 & * & \\
\hline 4 & * & \\
\hline 5 & & * \\
\hline 6 & & * \\
\hline 7 & & * \\
\hline 8 & * & \\
\hline 9 & & * \\
\hline 10 & * & \\
\hline 11 & * & \\
\hline 12 & * & \\
\hline 13 & * & \\
\hline 14 & & * \\
\hline 15 & 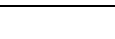 & * \\
\hline 16 & * & \\
\hline 17 & * & \\
\hline 18 & * & \\
\hline 19 & * & \\
\hline 20 & * & \\
\hline 21 & * & \\
\hline 22 & & * \\
\hline 23 & & * \\
\hline 24 & & * \\
\hline 25 & & * \\
\hline 26 & * & \\
\hline 27 & & * \\
\hline 28 & * & \\
\hline 29 & * & \\
\hline 30 & * & \\
\hline 31 & & * \\
\hline 32 & & * \\
\hline 33 & & * \\
\hline 34 & * & \\
\hline 35 & * & \\
\hline 36 & * & \\
\hline 37 & & * \\
\hline 38 & * & \\
\hline 39 & * & \\
\hline 40 & * & \\
\hline
\end{tabular}

Keterangan :

Cluster 1 : Miskin

Cluster 2: Fakir

\section{Penguujian Hasil}

Dari hasil cluster pada Tabel 11. Akan diuji dengan data training yang sudah memiliki label sebanyak 40 data. Adapun hasil perhitngan pengujian data training dengan metode K-Means dapat dilihat pada Tabel 12.

Tabel 7 centroid awal

\begin{tabular}{|c|c|c|c|c|c|c|c|c|c|c|c|c|c|c|c|}
\hline \multicolumn{1}{|c|}{ Centroid awal } & Pekerjaan & Pendapatan & PkI & Pdpt i & JA & Tggan & KR & Lantai & Dinding & Elektronik & Transportasi & Listrik & Biaya Listrik \\
\hline Centroid 1 (data ke-6) & 5 & 6 & 2 & 1 & 2 & 2 & 1 & 2 & 1 & 2 & 2 & 2 \\
\hline centroid 2 (data ke-33) & 6 & 6 & 0 & 0 & 1 & 1 & 2 & 2 & 1 & 5 & 0 & 0 \\
\hline \\
\hline
\end{tabular}


Tabel 12 Hasil Pengujian dengan metode K-Means

\begin{tabular}{|c|c|c|}
\hline Data ke-i & $\begin{array}{c}\text { Hasil perhitungan } \\
\text { K-Means }\end{array}$ & Golongan Data Training \\
\hline 1 & Miskin & Miskin \\
\hline 2 & Miskin & Fakir \\
\hline 3 & Miskin & Miskin \\
\hline 4 & Miskin & Miskin \\
\hline 5 & Fakir & Miskin \\
\hline 6 & Fakir & Fakir \\
\hline 7 & Fakir & Miskin \\
\hline 8 & Miskin & Fakir \\
\hline 9 & Fakir & Miskin \\
\hline 10 & Miskin & \\
\hline
\end{tabular}

Berdasarkan Tabel 9 dapat dilihat persentase untuk Correctly Clustering adalah sebesar $\mathbf{7 5 \%}$ sementara persentase untuk Incorrectly Clustering adalah sebesar 25\%. Dimana dari 40 data penerima zakat atau mustahiq, ada sebanyak 30 data berhasil di clustering dengan benar dan sebanyak 10 data tidak berhasil di clustering dengan benar.

\section{KESIMPULAN DAN SARAN}

5.1 Kesimpulan

1. Aplikasi penentuan golongan penerima zakat (mustahiq) yang dibuat dapat membantu lembaga menghasilkan laporan dengan cepat dan akurat karena pada sistem terdapat fitur Export to excel, dimana data dapat langsung di export dan dicetak.

2. Perhitungan algoritma K-Means dalam menentukan golongan penerima zakat (mustahiq) mampu menghasilkan tingkat akurasi dengan nilai $75 \%$. Pengujian algoritma ini dilakukan dengan membandingkan golongan pada data lama dengan golongan hasil clustering. Dimana dari 40 data penerima zakat atau mustahiq, ada sebanyak 30 data berhasil di clustering dengan benar.

3. Berdasarkan hasil pengujian aplikasi dengan menggunakan 3 browser yang berbeda, semua tampilan dan fungsi aplikasi dapat berjalan $100 \%$ pada 3 browser yaitu, Mozilla versi 71.0, Chrome versi 78.0.3904.108, dan Internet Explorer Windows 10.

\subsection{Saran}

1. Aplikasi penentuan golongan penerima zakat (mustahiq) ini perlu dilakukan perbandingan hasil pengelompokan dengan perhitungan metode lain seperti K-Medoids, K-NN, Single Linkage, Fuzzy C-Means dan metode lainnya.

2. Aplikasi ini menggunakan 13 kriteria. Aplikasi ini dapat dikembangkan dengan menambahkan kriteria.

3. Aplikasi ini hanya menentukan 2 golongan penerima zakat yaitu Fakir dan Miskin. Aplikasi dapat di kembangkan untuk golongan penerima zakat (mustahiq) yang lainnya yaitu Amil, Mu'allaf, Hamba Sahaya, Gharimin, Fisabilillah dan Ibnu sabil.

\section{DAFTAR PUSTAKA}

[1] Afrianty, I. and Umbara, R., 2016, November. Sistem Pendukung Keputusan (SPK) Menentukan Kelayakan Calon Penerima Zakat Menerapkan Multi-Factor Evaluation Process (MFEP). In Seminar Nasional Teknologi Informasi Komunikasi dan Industri.

[2] Sulastri, H. and Gufroni, A.I., 2017. Penerapan data mining dalam pengelompokan penderita thalassaemia. Jurnal Nasional Teknologi dan Sistem Informasi, 3(2), pp.299-305.

[3] Iswara, R.A., Santoso, E. and Rahayudi, B., 2017. Sistem Pendukung Keputusan Untuk Penentuan Mustahiq (Penerima Zakat) Menggunakan Metode Fuzzy AHP (F-AHP). Jurnal Pengembangan Teknologi Informasi dan Ilmu Komputer e-ISSN, 2548, p.964X.

[5] Mahmudi, A., Nataly, S. and Kusyanti, D.E., 2018. PENGELOMPOKAN PEKERJAAN PEMBENAHAN JARINGAN IRIGASI TERSIER DI KABUPATEN MALANG MENGGUNAKAN METODE K-MEANS CLUSTERING. Sinteks: Jurnal Teknik, 7(1), pp.9-15.

[6] Efendi, M., 2018. PENERAPAN METODE KMEANS CLUSTERING PADA SISTEM PENDUKUNG KEPUTUSAN PENENTUAN STATUS GIZI BATITA. JATI (Jurnal Mahasiswa Teknik Informatika),2(2), pp.184189.

[7] Auliasari, K. and Kertaningtyas, M., 2018. Studi Komparasi Klasifikasi Pola Tekstur citra Digital Menggunakan metode K-Means dan Naïve Bayes. Jurnal Informatika, 18(2), pp.175-185. 